\title{
Molecular interactions behind carbonate compaction
}

Piotr ZARZYCKI ${ }^{1}$, SteVEn PRIDE ${ }^{1}$, BENJAMIN GILBERT ${ }^{1}$

${ }^{1}$ Energy Geosciences Division, Lawrence Berkeley National

Laboratory, Berkeley, California, United States

Nearly half of the world's oil and gas reserves are located in carbonate sediments [1], and therefore the permeability of these sediments is of primary importance for the oil/gas extraction technologies. As the overburden pressure increases, the sediment porosity reduces along a complex mechano-chemical compaction pathway that often includes pressure solution, cementation, slow-crack growth and mineral stabilization [1]. However, we still do not know how these phenomena are coupled, in part due to a lack of molecular-level understanding of fundamental processes involved in the porosity-permeability reduction.

Here, we present a first molecular simulation of carbonate sediment compaction in the sub-micrometer-scale, at varying burial depth, and fluid composition. Our simulations show how the evolution of stress and strain tensors, porosity and permeability originate in interactions on the molecular scale.

When an irregular suspension of calcite grains in the electrolyte is squeezed under applied compressive stress, the interfacial hydration layers are pushed to the side as the calcite grains approach each other, allowing the calcite grains to come into direct contact. The development of the particleparticle contacts and increased rigidity of the hydrogen-bond network of pore water are responsible for increasing stiffness of sediment upon burial.

These findings are important in understanding and predicting the porosity-permeability relationship in the carbonate-based oil/gas reservoirs.

\section{References:}

[1] Croizé D., Renard F. and Gratier J.-P. (2013) Compaction and Porosity Reduction in Carbonates: A Review of Observations, Theory, and Experiments, in Advances in Geophysics, 54, 181-238, Elsevier Inc. 